\title{
CAPELO, Bernardette. Ce que mon cœur sait de la semence / O que meu coração sabe da semente. Edição bilingue. Paris: Convivium Lusophone, 2014.84p.
}

\section{Bernardette Capelo: o prodígio da semente}

\author{
A chave secreta \\ conhece todas as portas: \\ prodígio da semente. \\ (Bernardette Capelo)
}

Em 2014, Bernardette Capelo publicou, em edição bilingue, uma bela plaquette de poesia intitulada Ce que mon cour sait de la semence / O que meu coração sabe da semente, ilustrada com uma aguarela de Alberto Peixoto, e introduzida por um prefácio de Albano Martins ${ }^{1}$. O volume apresenta sessenta e um poemas, inspirados na técnica do haïku, a forma poética mais curta do mundo, considerada no Japão como a própria essência da poesia. Caracterizado como um poema breve, tradicional e popular, o haiku celebra o mundo efémero e a beleza de um instante, segundo o ritmo das estações, estabelecendo quase sempre uma relação com a natureza e com a evanescência das coisas. Geralmente, este tipo de poesia evoca uma estação (o "kigo") e descreve um instante do real, recorrendo a palavras muito simples. Os três autores mais conhecidos desta prática literária são Bashô (16441694), Issa (1763-1827), e Shiki (1867-1902), mas o género nunca deixou de inspirar um grande número de escritores ocidentais, nomeadamente contemporâneos como Philippe Jaccottet, Yves Bonnefoy, Jack Kerouac, entre outros. Por seu lado, Roland Barthes concebeu o haïku como um instantâneo fotográfico, assimilado a uma vibração ${ }^{2}$. Curiosamente, os sobreviventes das

\footnotetext{
1 Bernardette Capelo, Ce que mon cœur sait de la semence / O que meu coração sabe da semente, Paris, ed. Convivium Lusophone, 2014. O poeta e professor Alfredo Pérez Alencart, da Universidade de Salamanca, seleccionou e traduziu para castelhano 20 poemas deste volume, publicados em agosto de 2015 na revista Crear en Salamanca, in $<$ www. crearensalamanca.com/poemas-de-bernardette-capelo-seleccionados-ytraducidos-por-alfredo-perez-alencart-prefacio-de-albano-martins-ypinturas-de-miguel-elias/>

2 Consultar a este propósito Roland Barthes, L'empire des signes, Skira, Genève, 1970, e também La Préparation du roman I et II. Cours et séminaires au Collège de France (1978-1979 e 1979-1980), texto estabelecido, anotado e apresentado por Nathalie Léger, Paris, Seuil/ Imec, 2003 .
}

trincheiras da guerra de 1914-18, também escreveram haïkus, exprimindo, em três curtos versos, o sofrimento dos homens e todo o horror do conflito (En pleine figure - Haïkus de la guerre de 14-18. Antologia organizada por Dominique Chipot, com prefácio de Jean Rouaud, Paris, Editions Bruno Doucey, 2013).

Em geral, o haïku propõe três versos de dezessete sílabas $(5 / 7 / 5)$ que transmitem uma impressão fulgurante, resultante da emoção provocada pelo contacto privilegiado com a natureza. A composição respeita regras implícitas como a coesão interna e mobiliza um certo número de temas rigorosamente codificados. A arte do haïku baseia-se na concisão que pretende capturar a beleza de um instante fugitivo e recriar a ligação primordial com o mundo do ínfimo, caracterizando-se essencialmente pelo despojamento que recusa qualquer ornamentação. Segundo Bashô, um dos haikistas mais célebres, o poema perfeito deve revelar três dimensões: o imutável, a eternidade e o efémero, apresentando-se assim como um poema do instante, que confronta o presente com a eternidade e se revela atento ao detalhe, à contingência (segundo Barthes, o fundamento do haïku é justamente a contingência). Trata-se portanto de uma forma de escrita que privilegia a elipse e a brevidade, pondo o silêncio em palavras, de forma a traduzir o sabor do mundo e a intensidade de uma experiência fulgurante. Neste tipo de poesia, o sujeito apaga-se para ficar atento apenas à vibração do real, transformando-se em pura sensação, em potência emotiva.

Mesmo se não pretende elaborar haïkus, segundo a técnica exigida, Bernardette Capelo respeita no entanto o seu espírito. Os poemas deste volume assemelham-se assim a espelhos que reflectem o brilho de uma experiência essencial vivida na Tunísia, em Hammamet, durante o verão de 2012. No prólogo, a autora apresenta a génese da sua obra, indicando que, depois de ter passado alguns meses a estudar a técnica do haïku, a escrita se lhe impôs directamente em francês, para tocar "um terceiro espaço, onde tudo circula. Aí se toca o que é primordial, a evidência intuitiva, o instante, luminoso, dessa evidência" (p. 8). 
Bernardette Capelo evoca neste livro um espaço de grande beleza, exaltado pela sensibilidade do olhar, transmitindo a textura de um universo marcado pela espontaneidade e pelo inesperado que continuamente se esquiva. À escuta do mundo que a envolve, a palavra cristalina capta os detalhes minúsculos do real e valoriza o instante presente, partilhada entre a luz e as sombras, na evidência do simples, capaz de recriar o brilho que se esconde nos recantos mais obscuros da intensidade vivida.

O corpo poético é inaugurado pelo "ritual do jasmim: / revelação de um secreto / perfume do silêncio" (p.14). Estes três versos anunciam a tonalidade que vai definir toda a obra. A palavra "perfume" repete-se várias vezes ao longo das páginas e declina-se em perfume das flores, mas também perfume da viagem, perfume do mistério, perfume da abertura à alteridade, associando-se a outros termos recorrentes - como estrela, noite, vento, alegria, jardim, deserto, árvore, sol -, de forma a desenhar a densidade de uma percepção suspensa no tempo, inscrita no brilho intenso da paisagem, no conhecimento essencial que orienta o ritmo do livro e justifica o seu título, explicitado no fragmento 19:

\section{Meu jasmim exala \\ o que meu coração sabe da semente (p.50).}

O detalhe perceptivo é subjectivamente trabalhado através de um conjunto de imagens onde se define uma estreita relação entre o concreto e o abstracto, a sensação e o pensamento, apresentando por vezes um detalhe pictural que faz explodir as cores e os contrastes da natureza. Descobrimos assim o branco das cúpulas, o sol vermelho da terra africana, o amarelo das folhas que anunciam o outono, a cor rosa dos ventos, o cacto que é "pele da beleza" (p. 100), mas também "a noite profunda" (p.22), que por vezes se alonga (p. 32), ou ainda "o céu estrelado" (p.130), que assiste à partida do sujeito poético. Na sua brevidade, o poema exprime também uma percepção da natureza que pode traduzir uma subtil lição de vida:

\section{Docemente a voz \\ do vento diz: \\ sê como a estrela (p.44).}

Todo o livro se apresenta como o lugar de uma tensão que exalta a percepção emotiva associada à meditação, através do burilar de uma escrita partilhada entre a voz (ora "doce / como um perfume" (p. 66), ora murmúrio) e o silêncio comparado a "uma bruma" (p. 104), para ganhar a forma de um aforismo que condensa uma sabedoria antiquíssima, como podemos constatar nos seguintes versos:
A palmeira canta

a canção do vento:

ela sabe o oriente (p.46).

A leitura destes poemas de Bernardette Capelo - que alia concisão e clareza a um elegante pudor -, colocanos de imediato no âmago da maravilha provocada pelo mistério oriental e conduz-nos para os caminhos de uma sabedoria budista, reveladora de uma experiência singular do tempo e do ser. A intuição do instante convoca uma escrita que poderíamos designar como epifânica, em que o inesperado se confunde com um momento fora do tempo, susceptível de traduzir tanto a plenitude do ser como o esplendor da paisagem vislumbrada:

$$
\begin{aligned}
& \text { O sol vermelho mergulha } \\
& \text { na linha do horizonte - } \\
& \text { revela-se o seu mundo oculto (p. 60). }
\end{aligned}
$$

Atenta ao mundo elementar ("a doçura / da areia" (p. 102), "o céu estrelado" (p. 130), o vento, a palmeira, o deserto, o mar), a escrita poética desenha pacientemente um percurso que se inicia com "a claridade da alegria" (p.22), e atravessa todo o verão, caracterizado pela luz que se ergue "no fundo do horizonte" (p.56), pelo sopro do "vento verde / nas ramagens" (p. 70), ou pela "tarde calma / na pele" (p. 78), até chegar ao momento da partida que se aproxima, habilmente condensado nestes versos:

$$
\begin{aligned}
& \text { Quando chega Setembro } \\
& \text { estreito nos meus braços } \\
& \text { a errância da alegria (p. 90). }
\end{aligned}
$$

Este movimento de reconhecimento prolonga-se ainda na consciência do fim de um ciclo que não é tecido pela melancolia, mas surge antes como simples aceitação de uma evidência:
Digo outono:
é o tempo de recolher
as velas da alegria (p. 124).

Como é frequente no haïku japonês, os poemas de Bernardette Capelo declinam-se em função das estações, sempre atentos às formas da coincidência entre a reflexão e a sensação, referindo-se frequentemente aos olhos, à voz, mas também à pele, aos ombros, ao braço ou à mão que, ao anoitecer, levanta "alto a taça" (p.30) para celebrar a transparência, o estremecimento do crepúsculo no jardim. Descobrimos por vezes uma verdadeira encenação do corpo marcado pelo "estremecer/de um sorriso" (p.76), pelos movimentos da alma ou pelas feridas inscritas no fundo da memória: 
Estar aqui e ao mesmo tempo os meus olhos estão lá:

presente da memória (p. 114).

A sintaxe do visível manifesta quase sempre uma espécie de estado de graça onde se espraia a emoção da autora perante "a voz/do vento" (p.44), os "galos (que) anunciam / a aurora que se abre" (p. 54), ou diante da noite que se incendeia (p.68), depois do anoitecer no jardim, momento mágico em que "o chilrear dos pássaros / acorda as árvores" (p.62). Os versos assemelham-se assim ao que Michel Collot designa como "matéria-emoção", lembrando que a etimologia da palavra "emoção" exprime justamente um movimento de saída de si, de abertura ao mundo exterior para revelar toda a sua beleza. Desta forma, a poeta não se limita a reproduzir o que sentiu mas produz antes, pela magia do verbo, uma intensidade semelhante, revestida de uma qualidade estética, capaz de recriar uma nova emoção "puramente poética"3.

Entre o ver e o dizer, Bernardette Capelo convidanos a partilhar os traços de um itinerário deslumbrante $\mathrm{e}$ o fascínio por um espaço em que a experiência exterior se converte indubitavelmente em percurso íntimo, de serenidade e maravilha:

Os versos abrem-se Sobre a mesa - o cosmos se concentra (p. 134).

MARIA GRACIETE BESSE

Université de la Sorbonne - Paris IV

Recebido: 17 de janeiro de 2016 Aprovado: 22 de maio de 2016 Contato:mariagraciete7@aol.com

\footnotetext{
3 Michel Collot, La matière-émotion, Paris, PUF, 1997, p. 26-27.
} 